D) Check for updates

Cite this: Org. Biomol. Chem., 2022, 20,6007

Received 24th January 2022, Accepted 15th February 2022

DOI: $10.1039 / \mathrm{d} 2 \mathrm{ob00151a}$

rsc.li/obc

\title{
Modular synthesis of triazoles from 2-azidoacrylamides having a nucleophilic amino group †
}

\author{
Hinano Takemura, ${ }^{a}$ Gaku Orimoto, ${ }^{b}$ Akihiro Kobayashi, ${ }^{a}$, ${ }^{\text {T }}$ Takamitsu Hosoya (D) a and \\ Suguru Yoshida iD *b
}

\begin{abstract}
Assembling methods using 2-azidoacrylamides having a nucleophilic amino group are disclosed. Divergent transformations of the amine-type trivalent platform were accomplished with a wide variety of electrophiles to obtain a broad range of 2-azidoacrylamides involving a fluorosulfonyl group-containing trivalent platform. Consecutive click conjugations including triazole formation, thiol-ene-type 1,4addition, and SuFEx reactions realized the efficient assembly of easily available simple modules.
\end{abstract}

\section{Introduction}

Facile methods to assemble simple modules onto platform molecules having a number of functional groups for click chemistry are of great significance for the preparation of multifunctional compounds in broad research fields such as pharmaceutical science and chemical biology. ${ }^{1-4}$ Since click reactions have been in the construction of a vast chemical library and in the synthesis of chemical probes bearing reporter groups, various trivalent platform molecules for consecutive click reactions have been developed so far and an efficient consecutive click assembly using compact platforms is awaited (Fig. 1A). ${ }^{5,6}$

We recently succeeded in the synthesis of 2-azidoacrylamides 1 bearing an alkyne or a tertiary azido moiety as compact trivalent platforms (Fig. 1B). ${ }^{6 d}$ While 1,4-adducts were not obtained when nucleophiles including thiols and amines were treated with 2-azidoacrylamides 1, 1,4-addition of nucleophiles proceeded efficiently using 2-(1,2,3-triazol-1-yl)acrylamides 2 synthesized from azides 1 by the copper-catalyzed azide-alkyne cycloaddition (CuAAC) reaction with alkynes, clearly showing increased electrophilicity by triazole formation. We herein designed a compact 2-azidoacrylamide platform 5 possessing a sulfonyl fluoride moiety for the sulfur(vi) fluoride exchange (SUFEx) reaction, which is an emerging click

${ }^{a}$ Laboratory of Chemical Bioscience, Institute of Biomaterials and Bioengineering, Tokyo Medical and Dental University (TMDU), 2-3-10 Kanda-Surugadai, Chiyoda-ku, Tokyo 101-0062, Japan

${ }^{b}$ Department of Biological Science and Technology, Faculty of Advanced Engineering, Tokyo University of Science, 6-3-1 Niijuku, Katsushika-ku, Tokyo 125-8585, Japan. E-mail: s-yoshida@rs.tus.ac.jp

$\dagger$ Electronic supplementary information (ESI) available: Experimental procedures, characterization for new compounds including NMR spectra. See DOI: 10.1039/d2ob00151a reaction $^{7,8}$ (Fig. 1C). To achieve the synthesis of trivalent platform $\mathbf{5}$, we conceived a challenging and efficient synthetic route by hydroamination of ethenesulfonyl fluoride $(\mathbf{4})^{9}$ with biphilic 2-azidoacrylamides 3 having an electrophilic exomethylene moiety and a nucleophilic free-amino group, paying attention to the inferior electrophilicity of 2 -azidoacrylamides 1 compared to that of triazole-substituted acrylamides 2 . Since diverse transformations using a free amino group have been established so far, we also expected that amine-type platform 3 can serve as a useful platform to assemble simple modules.

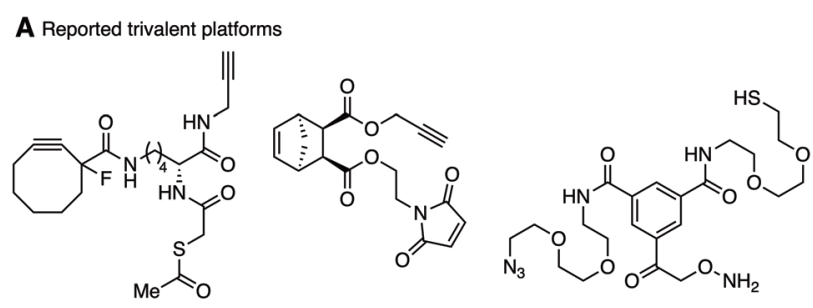

B Previous work: compact trivalent platforms [triazole formations \& Michael addition]
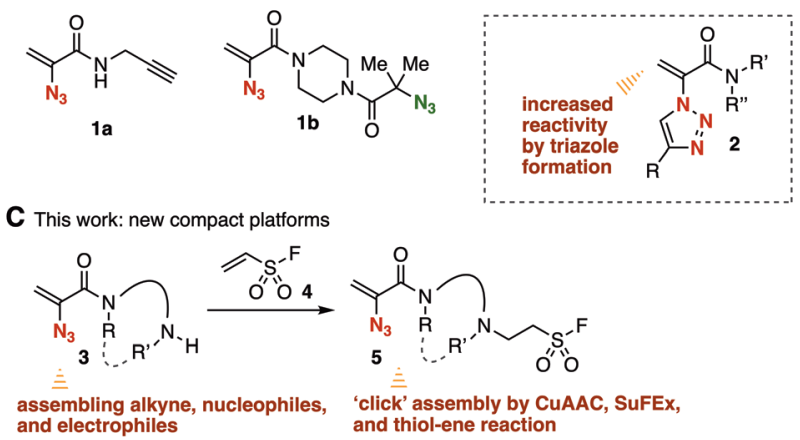

Fig. 1 (A) Trivalent platform molecules. (B) Previous study. (C) This work. 


\section{Results and discussion}

Synthesis of 2-azidoacrylamides having free amino groups

First, we succeeded in the synthesis of 2-azidoacrylamide 3a having a free secondary amino group (Fig. 2A). Treatment of 2-acrylamide $6 \mathbf{a}$ with trifluoroacetic acid in dichloromethane efficiently provided amine 3a after aqueous workup under basic conditions. Although gradual decomposition of amine 3a was observed at room temperature under argon, we fortunately isolated 3a with good purity after the aqueous workup without further purification. ${ }^{10}$

A wide range of amines $\mathbf{3} \mathbf{b}$-3e bearing 2-azidoacrylamide moieties were prepared from 2-azidoacrylic acid (7) and amines having tert-butoxycarbonyl (Boc) amide moieties in good yields (Fig. 2B). For example, tertiary amide $\mathbf{3 b}$ possessing a primary amino group was synthesized through condensation with 4-(tert-butoxycarbonylamino)piperizine using $\mathrm{PyBOP}^{11}$ followed by the treatment with trifluoroacetic acid in high yield. The synthesis of secondary amides $\mathbf{3 c}$ and $\mathbf{3 d}$ having a primary amino group was achieved. We found that gradual decomposition of primary amine $\mathbf{3 d}$ occurred at room temperature under argon, ${ }^{12}$ showing similar stability to secondary amine 3a. Also, acrylanilide 3e was synthesized via the condensation between 2-azidoacrylic acid (7) and 4-(tert-butoxycarbonylamino)aniline in moderate yield.

\section{Transformations of 2-azidoacrylamides having free amino groups}

Transformations of amine $\mathbf{3 a}$ with various electrophiles enabled us to synthesize a broad range of 2-azidoacrylamides

A

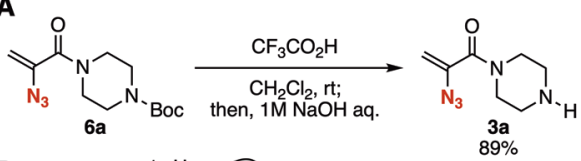

B
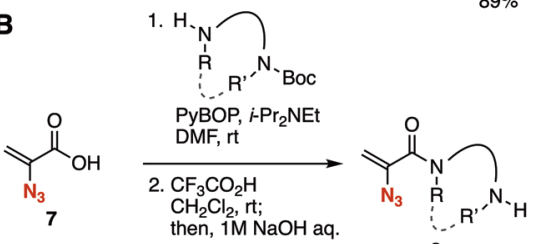

3

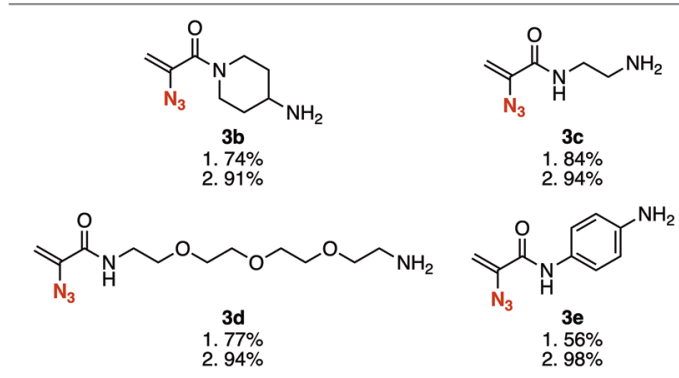

Fig. 2 Synthesis of amines 3. (A) Deprotection of the Boc moiety of $6 \mathbf{a}$. (B) Synthesis of various amines 3 from 2-azidoacrylic acid (7). PyBOP = (benzotriazol-1-yloxy)(trispyrrolidino)phosphonium hexafluorophosphate. See the ESI† for details. 9a-9i in moderate to good yields (Fig. 3). We accomplished the acetylation of amine 3a with acetic anhydride to provide amide 9a in good yield. Synthesis of amide $\mathbf{9 b}$ was achieved by the condensation between amine 3a and carboxylic acid $\mathbf{8 b}$ using PyBOP without damaging the 2-azidoacrylic amide moiety. Carbamate 9c was successfully prepared from amine $\mathbf{3 a}$ and isocyanate 8c under basic conditions. We also succeeded in the guanidination of amine 3a with 1-amidinopyrazole hydrochloride (8d) yielding guanidine 9d quantitatively. Sulfonamide 9e was also prepared from amine 3a using sulfonyl chloride 8e. Triazination of amine $\mathbf{3 a}$ with cyanuric chloride (8f) proceeded smoothly to provide triazine $9 \mathbf{f}$ in moderate yield. Also, we synthesized amine $\mathbf{9} \mathbf{g}$ by the reductive amination of amine $\mathbf{3 a}$ with aldehyde $\mathbf{8 g}$ using sodium triacetoxyborohydride as a reductant leaving the electrophilic 2-azidoacrylic amide moiety untouched. Arylation of amine 3a with benzyne generated in situ from $\boldsymbol{o}$-silylphenyl triflate $\mathbf{8 h}$ keeping
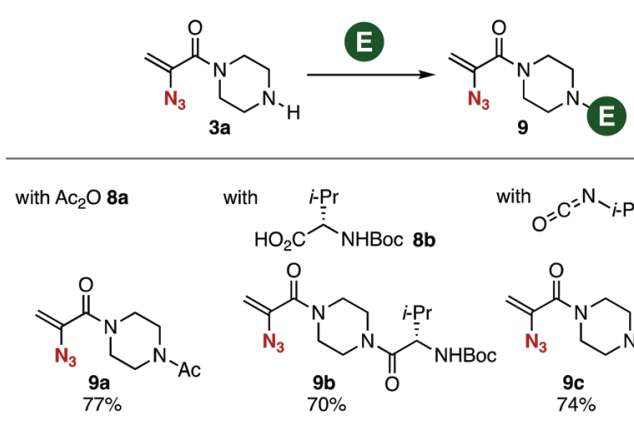
with $0=0=N_{-i-\operatorname{Pr}} 8 \mathrm{c}$

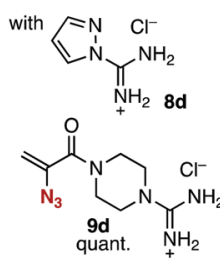<smiles>C=C(N)C(=O)N1CCN(S(=O)(=O)c2cccnc2)CC1</smiles><smiles>Clc1nc(Cl)nc(Cl)n1</smiles><smiles>C=C(N)C(=O)N1CCN(c2nc(Cl)nc(Cl)n2)CC1</smiles><smiles>[18OH]c1ccc(Br)s1</smiles><smiles>C=C(N)C(=O)N1CCN(Cc2cccs2)CC1</smiles><smiles>C=C(N)C(=O)N1CCN(c2ccccc2)CC1</smiles><smiles>C=C(N)C(=O)N1CCN(CC(C(=O)N2CCN(C(=O)OC(C)(C)C)CC2)n2cc([Ge])nn2)CC1</smiles>

Fig. 3 Synthesis of various 2-azidoacrylamides 9. See the ESI† for details. 
the azido group unreacted, although azides generally react with benzyne to afford benzotriazoles. ${ }^{13}$ Furthermore, we realized the 1,4-addition of amine 3a with 2-(triazolyl)acrylamide $\mathbf{8 i}$, which was prepared from 1-(2-azidoacryl)-4-(tert-butoxycarbonyl)piperazine (6a) and 4-tolylacetylene by the CuAAC reaction $^{14}$ in our previous study. ${ }^{6 d}$ This result clearly showed that a wide variety of 2-azidoacrylamides can be prepared by sequential transformations using 2-azidoacrylamide-type platforms and alkynes in a modular synthetic manner.

Subsequent transformations of 2-azidoacrylamides 9 led to the efficient assembly of simple modules (Fig. 4). The CuAAC reaction of azide $\mathbf{9} \mathbf{g}$ with alkyne $\mathbf{1 0 a}$ efficiently took place affording 1,2,3-triazole $\mathbf{1 1}$ in a quantitative yield. We then achieved the synthesis of amine 13 by the 1,4-addition of 2(triazolyl)acrylamide 11 with $n$-butylamine (12) in high yield. These results indicated that diverse 2-(triazolyl)acrylamides can be synthesized from 2-azidoacrylamide 3a, electrophiles, alkynes, and nucleophiles in three steps.

\section{Synthesis of 2-azidoacrylamides having sulfonyl fluoride moieties}

The conjugate addition of amines with ethenesulfonyl fluoride (4) realized the preparation of novel trivalent platforms having an azido, an alkene, and a sulfonyl fluoride group (Fig. 5). Treatment of amine 3a with $\mathbf{4}$ in the presence of triethylamine provided trivalent platform $\mathbf{5 a}$ in an excellent yield leaving three clickable functional groups intact (Fig. 5A). We also accomplished the synthesis of dialkylated amine $\mathbf{5 b}$ from primary amine 3d with $\mathbf{4}$ in moderate yield (Fig. 5B). These

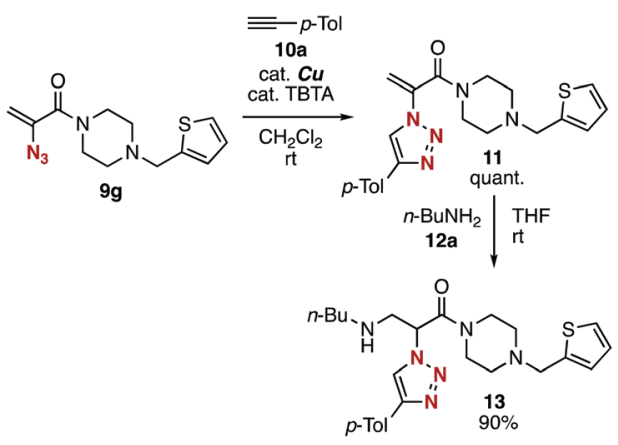

Fig. 4 Synthesis of 2-(triazolyl)amide 13. TBTA = tris((1-benzyl-4-triazolyl)methyl)amine. See the $\mathrm{ESI} \dagger$ for details.

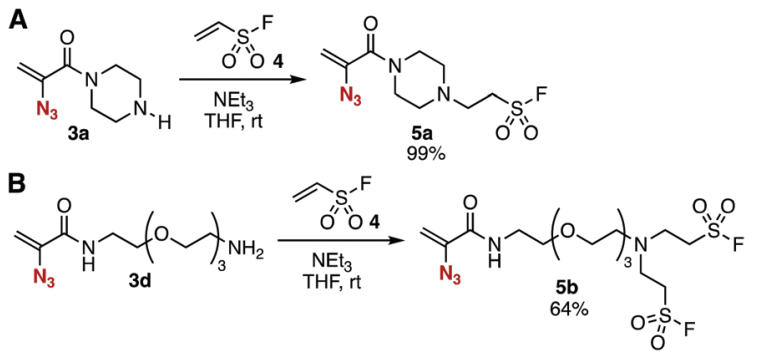

Fig. 5 Synthesis of sulfonyl fluorides 5. (A) Synthesis of 5a. (B) Synthesis of $5 b$.

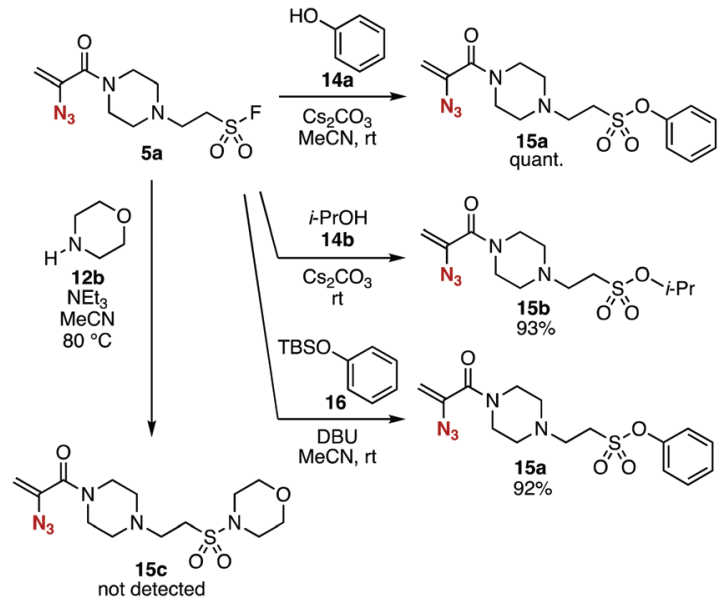

Fig. 6 SuFEx reactions of 5 a. See the ESI $\uparrow$ for details.

results suggested that amine-type trivalent platforms will help in the synthesis of a wide variety of clickable platform molecules with electrophiles bearing functional groups for the click chemistry despite the poor stability of amines 3 .

We succeeded in the synthesis of various 2-azidoacrylamides by the SuFEx reactions of sulfonyl fluoride 5a (Fig. 6). ${ }^{7,8}$ For example, sulfonyl fluoride 5a efficiently reacted with phenol (14a) under basic conditions to furnish phenyl sulfonate 15a quantitatively without reacting with the 2-azidoacrylamide moiety. Treatment of sulfonyl fluoride $\mathbf{5 a}$ with cesium carbonate in 2-propanol (14b) afforded isopropyl sulfonate 15b in high yield. We also achieved the synthesis of phenyl sulfonate 15a by the reaction of silyl ether 16 in the presence of 1,8diazabicyclo[5.4.0]undec-7-ene (DBU) keeping the electrophilic 2-azidoacrylamide moiety unreacted. Unfortunately, synthesizing sulfonyl amide 15c from sulfonyl fluoride 5a and amine 12b resulted in failure probably due to undesired side reactions such as 1,4-addition.

\section{Sequential conjugation using trivalent platform $5 \mathbf{a}$}

Sequential conjugation of trivalent platform 5a was achieved with alkyne 10a and amine 12a to provide 3-amino-2-triazolyl amide 18 having the sulfonyl fluoride moiety (Fig. 7). Indeed,

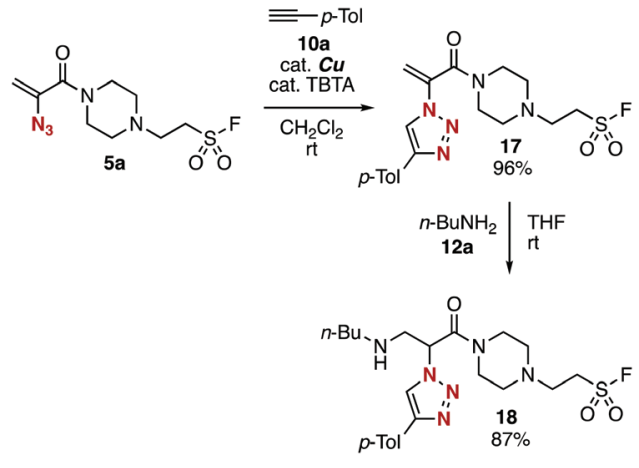

Fig. 7 Modular synthesis of 18. 
triazole formation of azide 5a with alkyne 10a catalyzed by tetrakis(acetonitrile)copper and TBTA occurred smoothly to yield 17 in an excellent yield. Then, we successfully prepared amine 18 by efficient conjugate addition using $n$-butylamine (12a) at room temperature without damaging the amine-susceptive fluorosulfonyl group. These results clearly showed that the 2-azidoacrylamide moiety can react with alkynes and nucleophiles prior to the SuFEx reaction.

The successful synthesis of 2-triazolylamide 21 by three component assembly indicated the good diversifiable reactivity of trivalent platform 5a (Fig. 8). The CuAAC reaction of phenyl sulfonate 15a followed by the thiol-ene reaction ${ }^{15}$ with 20 promoted by a base took place efficiently to provide 2-triazolylamide 21 in high yield (Fig. 8A). Moreover, the three component assembly onto platform 5a with phenol (14a), alkyne 10a, and
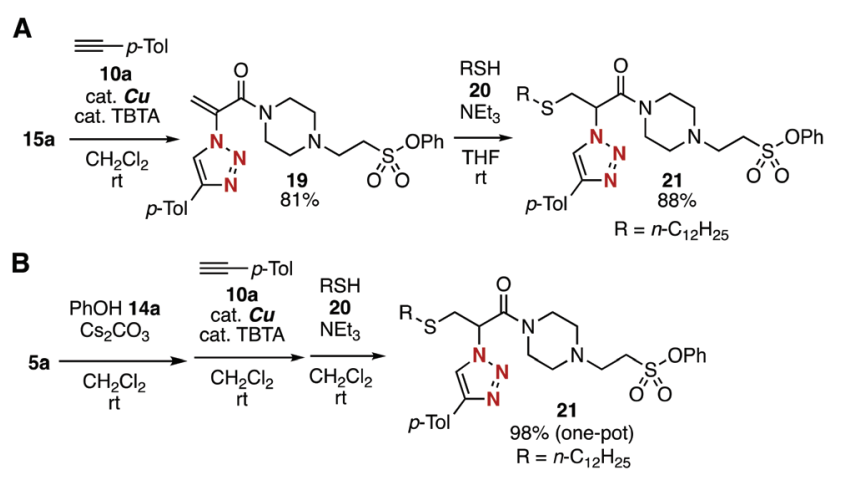

Fig. 8 Modular synthesis of 21. (A) Synthesis of 21 via isolated intermediates. (B) One-pot synthesis of 21 from $5 a$.

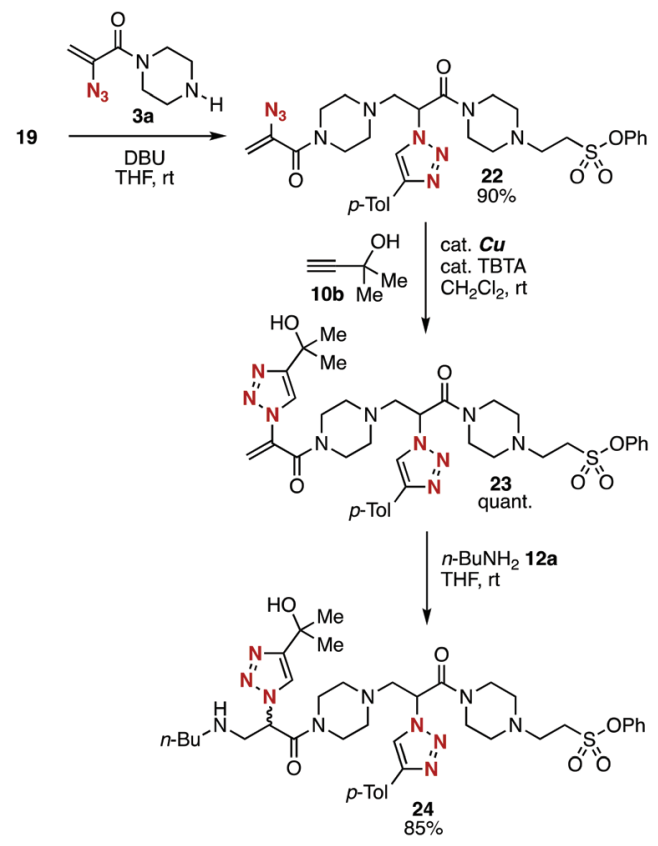

Fig. 9 Modular synthesis of multi(triazole) 24 . thiol 20 was achieved by the consecutive click reactions in a one-pot fashion (Fig. 8B).

\section{Synthesis of bis(triazole) 24}

To showcase the divergent potential of platforms 3 and 5 , we then examined a synthesis of diamide $\mathbf{2 4}$ from simple modules (Fig. 9). First, the treatment of amine-type platform 3a with 2-(triazolyl)acrylamide 19 synthesized from trivalent platform 5a, silyl ether 16, and alkyne 10a provided diamide 22 in good yield. Second, CuAAC reaction of diamide 22 proceeded smoothly without damaging amino, triazolyl, and phenoxysulfonyl groups. Third, amine $\mathbf{2 4}$ was synthesized efficiently as a mixture of diastereomers by the conjugate addition of $n$-butylamine (12a) with 2-(triazolyl)acrylamide 23. The good reactivity of 2-(triazolyl)acrylamide 23 as a Michael acceptor will allow us to repeat the conjugation using amine-type platforms 3 to synthesize multi(triazole)s in an iterative manner. Diamide $\mathbf{2 4}$ was prepared from trivalent platforms $\mathbf{3 a}$ and $\mathbf{5 a}$, alkynes 10a and 10b, amine 12a, and silyl ether 16 in 5 steps. Since alkynes, phenols, silyl ethers, and nucleophiles for 1,4addition are easily available, the efficient modular synthetic method will be used for synthesizing diverse multi(triazole)s in an iterative manner from simple modules.

\section{Conclusions}

In summary, we synthesized novel trivalent platforms 5 having azido, alkene, and fluorosulfonyl groups through 2-azidoacrylamides having a free amino group. A wide variety of triazoles were synthesized from trivalent platforms $\mathbf{5}$ and simple modules by click reactions. Since diverse multi(triazole)s can be prepared in a modular synthetic manner, the combinatorial chemistry using trivalent platforms will be used in constructing a vast chemical library of mid-sized multi(triazole)s. Further studies on the transformations of trivalent platforms 3 and 5 involving the scope and limitations are ongoing in our laboratory.

\section{Conflicts of interest}

There are no conflicts to declare.

\section{Acknowledgements}

The authors thank Dr Yuki Sakata at Tokyo Medical and Dental University for HRMS analyses. This work was supported by JSPS KAKENHI Grant Number JP19K05451 (C; S. Y.), the Naito Foundation (S. Y.), the Japan Agency for Medical Research and Development (AMED) under Grant Number JP21am0101098 (Platform Project for Supporting Drug Discovery and Life Science Research, BINDS), and the Cooperative Research Project of Research Center for Biomedical Engineering. 


\section{Notes and references}

1 J. Lahann, Click Chemistry for Biotechnology and Materials Science, John Wiley \& Sons, West Sussex, 2009.

2 For reviews of sequential click reactions, see: (a) A.-C. Knall and C. Slugovc, Chem. Soc. Rev., 2013, 42, 5131; (b) Z.-J. Zheng, D. Wang, Z. Xu and L.-W. Xu, Beilstein J. Org. Chem., 2015, 11, 2557; (c) S. Yoshida, Org. Biomol. Chem., 2020, 18, 1550; (d) D. Sato, Z. Wu, H. Fujita, J. S. Lindsey, D. Sato, Z. Wu, H. Fujita and J. S. Lindsey, Organics, 2021, 2, 161.

3 For recent examples of sequential click reactions, see: (a) I. E. Valverde, A. F. Delmas and V. Aucagne, Tetrahedron, 2009, 65, 7597; (b) B. C. Sanders, F. Friscourt, P. A. Ledin, N. E. Mbua, S. Arumugam, J. Guo, T. J. Boltje, V. V. Popik and G.-J. Boons, J. Am. Chem. Soc., 2011, 133, 949; (c) J. Dommerholt, O. van Rooijen, A. Borrmann, C. F. Guerra, F. M. Bickelhaupt and F. L. van Delft, Nat. Commun., 2014, 5, 5378; (d) P. R. Werkhoven, H. van de Langemheen, S. van der Wal, J. A. W. Kruijtzer and R. M. J. Liskamp, J. Pept. Sci., 2014, 20, 235; (e) M. Robert, J. Vallée, P. Majkut, D. Krause, M. Gerrits and C. P. R. Hackenberger, Chem. - Eur. J., 2015, 21, 970; (f) R. R. Ramsubhag and G. B. Dudley, Org. Biomol. Chem., 2016, 14, 5028; $(g)$ D. A. Sutton, S.-H. Yu, R. Steet and V. V. Popik, Chem. Commun., 2016, 52, 553; (h) N. Münster, P. Nikodemiak and U. Koert, Org. Lett., 2016, 18, 4296; (i) D. Svatunek, N. Houszka, T. A. Hamlin, F. M. Bickelhaupt and H. Mikula, Chem. - Eur. J., 2019, 25, 754.

4 For our recent studies on click chemistry, see: (a) S. Yoshida, T. Kuribara, H. Ito, T. Meguro, Y. Nishiyama, F. Karaki, Y. Hatakeyama, Y. Koike, I. Kii and T. Hosoya, Chem. Commun., 2019, 55, 3556; (b) K. Adachi, T. Meguro, Y. Sakata, K. Igawa, K. Tomooka, T. Hosoya and S. Yoshida, Chem. Commun., 2020, 56, 9823; (c) N. Makio, T. Kuribara, K. Adachi, Y. Hatakeyama, T. Meguro, Y. Sakata, K. Igawa, K. Tomooka, T. Hosoya and S. Yoshida, Chem. Commun., 2020, 56, 11449; and references therein.

5 For recent examples of sequential click reactions using trivalent platforms, see: (a) V. Vaněk, J. Pícha, B. Fabre, M. Buděšínský, M. Lepšík and J. Jiráček, Eur. J. Org. Chem., 2015, 3689; (b) B. Fabre, J. Pícha, V. Vaněk, M. Buděšínský and J. Jiráček, Molecules, 2015, 20, 19310; (c) B. Fabre, J. Pícha, V. Vaněk, I. Selicharová, M. Chrudinová, M. Collinsová, L. Žáková, M. Buděšínský and J. Jiráček, $A C S$ Comb. Sci., 2016, 18, 710; (d) A.-C. Knall, M. Hollauf, R. Saf and C. Slugovc, Org. Biomol. Chem., 2016, 14, 10576; (e) T. Yokoi, H. Tanimoto, T. Ueda, T. Morimoto and K. Kakiuchi, J. Org. Chem., 2018, 83, 12103; (f) T. Yokoi, T. Ueda, H. Tanimoto, T. Morimoto and K. Kakiuchi, Chem. Commun., 2019, 55, 1891; $(g)$ K. Maegawa, H. Tanimoto, S. Onishi, T. Tomohiro, T. Morimoto and K. Kakiuchi, Org. Chem. Front., 2021, 8, 5793.

6 For our recent studies on sequential click reactions using trior tetravalent platforms, see: (a) T. Meguro, Y. Sakata, T. Morita, T. Hosoya and S. Yoshida, Chem. Commun., 2020,
56, 4720; (b) N. Terashima, Y. Sakata, T. Meguro, T. Hosoya and S. Yoshida, Chem. Commun., 2020, 56, 14003; (c) H. Takemura, S. Goto, T. Hosoya and S. Yoshida, Chem. Commun., 2020, 56, 15541; (d) S. Yoshida, Y. Sakata, Y. Misawa, T. Morita, T. Kuribara, H. Ito, Y. Koike, I. Kii and T. Hosoya, Chem. Commun., 2021, 57, 899; and references therein.

7 For reviews of the SuFEx chemistry, see: (a) J. Dong, L. Krasnova, M. G. Finn and K. B. Sharpless, Angew. Chem., Int. Ed., 2014, 53, 9430; (b) A. S. Barrow, C. J. Smedley, Q. Zheng, S. Li, J. Dongd and J. E. Moses, Chem. Soc. Rev., 2019, 48, 4731; (c) Y.-P. Meng, S.-M. Wang, W.-Y. Fang, Z.-Z. Xie, J. Leng, H. Alsulami and H.-L. Qin, Synthesis, 2020, 673.

8 For recent examples of the SuFEx chemistry, see: (a) R. Zelli, S. Tommasone, P. Dumy, A. Marra and A. Dondoni, Eur. J. Org. Chem., 2016, 5102; (b) Q. Chen, P. Mayer and H. Mayr, Angew. Chem., Int. Ed., 2016, 55, 12664; (c) H.-L. Qin, Q. Zheng, G. A. L. Bare, P. Wu and K. B. Sharpless, Angew. Chem., Int. Ed., 2016, 55, 14155; (d) Q. Zheng, J. Dong and K. B. Sharpless, J. Org. Chem., 2016, 81, 11360; (e) X. Chen, G.-F. Zha, G. A. L. Bare, J. Leng, S.-M. Wang and H.-L. Qin, Adv. Synth. Catal., 2017, 359, 3254; (f) H. Wang, F. Zhou, G. Ren, Q. Zheng, H. Chen, B. Gao, L. Klivansky, Y. Liu, B. Wu, Q. Xu, J. Lu, K. B. Sharpless and P. Wu, Angew. Chem., Int. Ed., 2017, 56, 11203; $(g)$ J. Leng and H.-L. Qin, Chem. Commun., 2018, 54, 4477; (h) C. J. Smedley, M.-C. Giel, A. Molino, A. S. Barrow, D. J. D. Wilson and J. E. Moses, Chem. Commun., 2018, 54, 6020; ( $i$ ) D. Gahtory, R. Sen, S. Pujari, S. Li, Q. Zheng, J. E. Moses, K. B. Sharpless and H. Zuilhof, Chem. - Eur. J., 2018, 24, 10550; $(j)$ J. Thomas and V. V. Fokin, Org. Lett., 2018, 20, 3749; ( $k$ ) X. Zhang, B. Moku, J. Leng, K. P. Rakesh and H.-L. Qin, Eur. J. Org. Chem., 2019, 1763; (l) C. Li, Y. Zheng, K. P. Rakesh and H.-L. Qin, Chem. Commun., 2020, 56, 8075; $(m)$ M.-C. Giel, C. J. Smedley, E. R. R. Mackie, T. Guo, J. Dong, T. P. Soares da Costa and J. E. Moses, Angew. Chem., Int. Ed., 2020, 59, 1181; (n) S. Li, G. Li, B. Gao, S. P. Pujari, X. Chen, H. Kim, F. Zhou, L. M. Klivansky, Y. Liu, H. Driss, D.-D. Liang, J. Lu, P. Wu, H. Zuilhof, J. Moses and K. B. Sharpless, Nat. Chem., 2021, 13, 858.

9 (a) B. M. Gladshtein, E. I. Polyanskaya and L. Z. Soborovskii, Zh. Obshch. Khim., 1961, 31, 855; (b) J. A. Hyatt and J. J. Krutak, J. Org. Chem., 1977, 42, 169.

10 When 3a was placed at room temperature under argon for 3 days, we observed that $65 \%$ of 3 a was decomposed.

11 J. Coste, D. Le-Nguyen and B. Castro, Tetrahedron Lett., 1990, 31, 205.

12 When 3d was placed at room temperature under argon for 3 days, we observed that $66 \%$ of $3 \mathbf{d}$ was decomposed.

13 F. Shi, J. P. Waldo, Y. Chen and R. C. Larock, Org. Lett., 2008, 10, 2409.

14 (a) C. W. Tornøe, C. Christensen and M. Meldal, J. Org. Chem., 2002, 67, 3057; (b) V. V. Rostovtsev, L. G. Green, V. V. Fokin and K. B. Sharpless, Angew. Chem., Int. Ed., 2002, 41, 2596; (c) T. R. Chan, R. Hilgraf, K. B. Sharpless and V. V. Fokin, Org. Lett., 2004, 6, 2853.

15 A. B. Lowe, Polym. Chem., 2014, 5, 4820. 